\title{
OPTIONAL TIME-OF-USE PRICING CAN BE PARETO SUPERIOR OR PARETO INFERIOR
}

\author{
Jeffrey K. MACKIE-MASON \\ University of Michigan, Ann Harbor, MI 48109, USA \\ National Bureau of.Economic Research, Cambridge, MA 02138, USA
}

\begin{abstract}
Many public utilities offer a choice between time-of-use and flat rates. 'Two points are established: (1) optional TOU (time-of-use) schedules exist that Pareto dominate both mandatory flat and mandatory TOU rates; but, (2) optional TOU prices based on marginal costs can be welfare-decreasing, even Pareto inferior.
\end{abstract}

\section{Introduction}

Despite time-dependent production costs, public utilities often sell services (such as telephoning and electricity) at a flat rate throughout the day. Even when time-of-use (TOU) rates exist, customers frequently have the option to choose between TOU and flat rates. ${ }^{1}$ With no metering costs, marginal-cost TOU pricing is Pareto efficient. However, typically there are substantial metering costs, which sometimes outweigh the benefits of marginal-cost pricing. An argument for optional TOU rates is that customers can choose to pay the metering costs only when the benefits of time-dependent prices are sufficient.

It might seem that optional TOU rates should Pareto dominate both mandatory flat and mandatory TOU rates. Consider starting with mandatory flat rates, then offering customers a choice between the original flat rate or a TOU schedule (customers pay their own metering costs). Those who choose TOU are (weakly) better off by revealed preference; those who don't switch are indifferent. The same type of argument can be made for the comparison between optional and mandatory TOU rates.

In fact optional TOU rates may be Pareto inferior to both mandatory flat and mandatory TOU rates. The flaw in the example is that utility profits may change. Those who choose TOU will tend to be those with low peak-period demands (if the TOU rate moves toward marginal-cost pricing). The flat rate will no longer cover the costs of the self-selected peak-period users who remain on flat rates. Either profits fall or the flat rate must increase, making some customers worse off. The central idea is that in a self-selecting equilibrium, individuals choose based on private gain. Their private choices may impose non-pecuniary externalities on others, so social welfare can fall.

I characterize the welfare possibilities by first showing the optional TOU rates that are Pareto superior do exist. However, when metering costs are positive, the optimal rate design problem has not been solved. Therefore, I then show that optional TOU can be Pareto inferior for the natural case in which TOU rates are equal to marginal cost, and flat rates cover the costs of those on flat rates.

1 TOU electricity and local telephoning rates in Europe and the U.S. are usually optional. Long-distance telephone rates are the exception. 


\section{Optional TOU can be Pareto superior}

Suppose there are morning and afternoon periods, with consumption $x_{\mathrm{M}}^{i}$ and $x_{\mathrm{A}}^{i}$ for individual $i$. User costs for each period are $u_{\mathrm{M}}$ and $u_{\mathrm{A}}$ per unit, and the marginal cost of capacity is $k$ per unit. Assume that afternoon is the peak demand period under all pricing rulcs considered, and that all capacity is used in long-run equilibrium, so that capacity $K$ is equal to $\sum_{i} x_{\mathrm{A}}^{i}$. I indicate a pair of morning and afternoon prices by $p^{\mathrm{MF}}, p^{\mathrm{MT}}$, or $p^{\mathrm{OT}}$ under mandatory flat, mandatory TOU and optional TOU rates, respectively. Subscripts indicate period prices when necessary. A flat rate is indicated by $\bar{p}$.

That OT rates can Pareto dominate MF rates is not surprising. If the same flat rate is offered in both cases, then by revealed preference, any one who chooses TOU is better off and the other customers are indifferent. We need only establish that firm profits do not fall.

Result 1. If the current mandatory flat-rate price satisfies $u_{M}<\vec{p}^{\mathrm{MF}}<u_{A}+k$, and if all customers have positive demand during the afternoon period, then there exists an optional TOU schedule that Pareto dominates the $M F$ schedule.

Proof. $^{2}$ Offer the same flat rate $(\bar{p})$ under both MF and OT. Offer a morning price such that $p_{\mathrm{M}}^{\mathrm{OT}}>u_{\mathrm{M}}$. Find the customer who has the highest ratio of morning to afternoon consumption on flat rates; call this person $\beta$. Offer an afternoon price such that if $\beta$ chooses TOU rates and consumes the same quantities as before, she will have the same total expenditure [i.e., let $p_{\mathrm{A}}^{\mathrm{OT}}=\bar{p}+(\bar{p}-$ $\left.p_{\mathrm{M}}^{\mathrm{OT}}\right) *\left(x_{\mathrm{M}}^{\beta}(\bar{p}, \bar{p}) / x_{\mathrm{A}}^{\beta}(\bar{p}, \bar{p})\right)$ ]. If $\beta$ doesn't change consumption quantities, she is indifferent, and utility profits don't change. In general, however, $\beta$ will consumer more morning services and lower afternoon services at the new prices, and increase her surplus. Since morning services are priced above marginal cost, and afternoon services below, these consumption changes will increase utility profits.

Suppose another customer, $\alpha$, does choose TOU. By revealed preference, $\alpha$ must be weakly better off. Expenditures by $\alpha$ would be higher to obtain his original quantities, since his ratio of morning to afternoon is lower than $\beta$ 's, thus if $\alpha$ doesn't change his consumption bundle, the utility earns higher profits. If $\alpha$ increases morning consumption and decreases afternoon consumption, profits will be even greater.

An OT schedule that Pareto dominates MT rates also exists, although if TOU rates are equal to marginal costs the result requires a non-convexity such as metering costs.

Result 2. Suppose that mandatory TOU rates are equal to marginal cost $\left(p_{\mathrm{M}}^{\mathrm{MT}}=u_{\mathrm{M}}, p_{\mathrm{A}}^{\mathrm{MT}}=u_{\mathrm{A}}+k\right)$, that marginal costs are constant, and that each metered customer pays the metering cost, $p_{0}$. Then there exists an optional TOU schedule that Pareto dominates the MT schedule.

Proof. Under MT rates the utility earns zero profits. For each customer, determine the flat-rate price, $\bar{p}_{i}^{\text {OT }}$ such that the customer's desired expenditure at that price equals the total cost for her desircd quantitics. With constant marginal costs, $\bar{p}_{i}^{\mathrm{OT}}$ must be a weighted average of $p_{\mathrm{M}}^{\mathrm{MT}}$ and $p_{\mathrm{A}}^{\mathrm{MT}}$ for each customer, so $p_{\mathrm{M}}^{\mathrm{MT}}<\bar{p}_{i}^{\mathrm{OT}}<p_{\mathrm{A}}^{\mathrm{MT}}$ for all $i$. Denote by $\alpha$ the person with the highest ratio of afternoon to morning consumption, and offer a flat rate of $\bar{p}_{\alpha}^{\text {OT }}$. Person $\alpha$ will choose flat rates if metering costs are high enough, and will be (weakly) better off. The utility's profits do not change by definition.

\footnotetext{
${ }^{2}$ This result has been shown in independently by Train (1989).
} 
If any other customer chooses flat rates, utility profits increase because her ratio $x_{\mathrm{A}}^{i} / x_{\mathrm{M}}^{i}$ is lower than the break-even ratio, $x_{\mathrm{A}}^{\alpha} / x_{\mathrm{M}}^{\alpha}$, and $u_{\mathrm{A}}+k>\bar{p}_{\alpha}^{\mathrm{OT}}>u_{\mathrm{M}}$. Thus, all customers are better off or indifferent, and utility profits stay the same or increase.

\section{Optional TOU can be Pareto inferior}

OT rate schedules always exist that Pareto dominate MF and (if there are metering costs) MT rates. Why isn't optional TOU pricing in use everywhere? The optimal design of a self-selecting rate schedule with metering costs is quite difficult; no general solution has been proposed. ${ }^{3}$ I now show that an OT schedule based on standard rate design principles can yield lower welfare than MF or MT, even to the extent of being Pareto inferior.

I consider 'fully-distributed cost' pricing, which is a very common regulatory rate-setting mechanism. ${ }^{4}$ TOU rates are set at marginal user cost plus the average capacity cost in the peak period: $p_{\mathrm{M}}^{\mathrm{OT}}=u_{\mathrm{M}}$, and $p_{\mathrm{A}}^{\mathrm{OT}}=u_{\mathrm{A}}+c_{k}(K)$, where $c_{k}(K)$ is the average unit cost of capacity given that $K$ units are installed. The flat-rate is average cost for those users facing flat rates.

Result 3. If average capacity costs are non-decreasing, metering costs are positive, and prices are set according to the fully-distributed-cost principle, then optional TOU pricing can be Pareto inferior to mandatory flat-rate pricing.

Proof. ${ }^{5}$ Assume there are only two customers, one who buys only morning services (person $\beta$ ), and another who buys only afternoon services (person $\alpha$ ). Person $\alpha$ never chooses TOU rates because he would be charged the highest possible price $\left(u_{\mathrm{A}}+c_{k}\right)$ plus the metering cost.

We can use the expenditure function to examine $\beta$ 's choice. If $\beta$ has income $Y_{\beta}$, she chooses TOU when

$$
Y_{\beta}-p_{0} \geq e_{\beta}\left(p^{\mathrm{OT}}, v_{\beta}\left(p^{\mathrm{MF}}, Y_{\beta}\right)\right)
$$

where $e_{\beta}(\cdot)$ and $v_{\beta}(\cdot)$ are her expenditure and indirect utility functions. Note that if $\beta$ chooses flat rates, the flat rate under OT would be the same as under MF because everyone would be paying flat rates in both cases. Hence, the correct choice comparison is between $p^{\mathrm{OT}}$ and $p^{\mathrm{MF}}$. (Other prices are suppressed because they are assumed to remain constant.) The left side is the disposable income she has on TOU rates after paying the metering cost. The right side is the amount of income she needs under TOU rates in order to be at least as well of as under the flat rates. Since $p_{\mathrm{M}}^{\mathrm{OT}}<p_{\mathrm{M}}^{\mathrm{MF}}$, condition (1) must hold for $p_{0}$. Pick $p_{0}$ so that (1) is an equality; now $\beta$ is indifferent; assign her to TOU rates.

Consider what happens to $\alpha$. The price charged to $\alpha$ must cover his user costs and the average capacity costs associated with serving his peak-period demand. The new equilibrium flat rate is $\bar{p}^{\mathrm{OT}}=u_{\mathrm{A}}+c_{k}(K)$ which is greater than the old flat rate, which averaged morning and afternoon consumption. ${ }^{6}$ Thus, $\alpha$ is worse off. The utility makes zero profits under both rules.

\footnotetext{
Oren et al. (1985) have worked out a non-linear, self-selecting schedule that is Ramsey-optimal, but only with no metering costs and declining marginal costs.

See, e.g., Brown and Sibley (1986).

A similar result for testing to discriminate in insurance markets has been derived by Borenstein (1989).

${ }^{6}$ At the higher price, $\alpha$ will reduce his afternoon consumption, thus lowering $K$ and possibly $c_{k}(K)$. However, $c_{k}$ cannot fall far enough for the new rate to be below the old flat rate; if it did his consumption would be as high as it was before, which is a contradiction.
} 
Pareto inferiority requires that $\beta$ be strictly indifferent towards OT rates. But the more general and important point is that aggregate welfare could decrease. For OT rates to decrease welfare according to the compensation principle, we need

$$
\left[Y_{\beta}-p_{0}-e_{\beta}\left(p^{\mathrm{OT}}, v_{\beta}\left(p^{\mathrm{MF}}, Y_{\beta}\right)\right]<\left[e_{\alpha}\left(p^{\mathrm{OT}}, v_{\alpha}\left(p^{\mathrm{MF}}, Y_{\alpha}\right)\right)-Y_{\alpha}\right]\right.
$$

that is, for the aggregate money-metric utility loss of the afternoon customers to outweigh the gain for the morning customers. The left side is the condition for $\beta$ to choose TOU, and thus is nonnegative in a separating equilibrium. The right side is always nonnegative (otherwise $\alpha$ would also switch), so its is clear that a welfare decrease is always possible, for some values of $p_{0}$.

Welfare can decrease when the 'instant winners' phenomenon is severe. Instant winners are customers who consume primarily off-peak services, and thus are heavily subsidizing the on-peak users under flat rates. The private welfare gain by customers who choose metering may be mostly a transfer (undoing the cross-subsidy) which does not increase social welfare, but the metering uses real resources. Thus welfare can fall.

Optional TOU pricing can also reduce welfare relative to a mandatory TOU schedule if there are metering costs:

Result 4. If metering costs are positive and capacity costs are increasing, then optional TOU pricing can be Pareto inferior to mandatory TOU pricing.

Proof. Ignore metering costs for a moment. Customers that choose flat rates now pay average rather than marginal cost, driving a wedge between private and social value. Since the firm earns zero profits, customers must bear the loss in surplus. If capacity costs are constant then prices do not change for those who remain on TOU rates, so those who chose flat rates must be worse off. Customers will consume more peak-period services under flat rates than they did under TOU rates, so capacity costs increase, and the flat rate customers must be even worse off because their price must rise to cover their average costs. However, the flat-rate customers gain by avoiding the fixed metering charge. Thus, for some metering cost, there is an equilibrium flat rate that leaves at least one customer indifferent between flat and TOU rates, and none who are made better off by flat rates.

Put the indifferent customers on flat rates. With a lower price for afternoon consumption and more diposable income (no metering charge), their afternoon consumption increases. The per-unit charge $c_{k}(K)$ thus increases, raising the afternoon price to customers who remain on TOU rates and reducing their welfare. The firm receives zero profits under both schemes.

The intuition behind this result is that some customers are willing to suffer inefficiencies in order to avoid the metering charge; their net welfare gain may be small or even zero. However, the behavior of those who opt out of TOU rates may have spillover effects on the TOU customers by raising the capacity cost. The rate schedule choice is determined by private welfare gain; the public spillover costs are ignored, and may outweigh the private gain.

\section{Conclusion.}

TOU pricing equates marginal costs to marginal valuations. However, the gains may not justify metering costs. One suggested approach is to offer an optional TOU schedule. Then, only those customers for whom the efficiency gains exceed the metering costs will choose TOU. The results 
derived above establish two points: (1) optional TOU schedules exist that Pareto dominate both mandatory flat and mandatory TOU rates; but, (2) a welfare improvement is not guaranteed. Plausible optional TOU schedules can decrease welfare, even to the point of Pareto inferiority. Further research on the general design of optimal self-selecting TOU rate schedules is warranted.

\section{References}

Borenstein, S., 1989, The economics of costly risk sorting in competitive insurance markets, International Review of Law and Economics 9.

Brown, S. and D. Sibley, 1986, The theory of public utility pricing (Cambridge University Press, Cambridge).

Oren, S., S. Smith and R. Wilson, 1985, Capacity pricing, Econometrica 53, 545-566.

Train, K., 1989, Pareto superior time-of-use prices, Working paper (university of California, Berkeley, CA). 